\title{
One-Year Follow-up Results of Smoking Cessation Outpatient Clinic: Factors Affecting the Cessation of Smoking
}

\author{
Zehra Yaşar ${ }^{1}$ Özlem Kar Kurt ${ }^{1}$, Fahrettin Talay ${ }^{1}$, Aysel Kargı ${ }^{2}$ \\ ${ }^{1}$ Department of Pulmonary Disease, Abant İzzet Baysal University Faculty of Medicine, Bolu, Turkey \\ ${ }^{2}$ Islahiye State Hospital, Clinic of Pulmonary Disease, Gaziantep, Turkey
}

\begin{abstract}
Objective: The aim was to investigate the factors affecting the quitting smoking success of the patients followed in the smoking cessation outpatient clinic and the rate of quitting smoking in this clinic.

Methods: From the 320 cases who applied to the smoking cessation clinic, 241 cases with a 12 month follow-up completed between June 2011 and June 2012 were included in the study. Routine biochemical and hematological tests, respiratory function test, electrocardiography, and posteroanterior chest radiography were requested from the cases. Moreover, the cases were requested to complete the Fagerstrom nicotine dependence test, anxiety and depression assessment scale and the outpatient clinic's form, including demographic data. The medicines taken and the duration of use were recorded. The quitting smoking success of the patients and the factors affecting this success were evaluated.

Results: Generally, at the end of the first year, the rate of quitting smoking was $37.3 \%$. The demographic characteristics of the groups who quit smoking and who failed to quit smoking were similar. Fagerstrom dependence degree $(p<0.001)$ and the number of cigarettes smoked at the workplace $(p<0.001)$ were higher. The individuals included in the group who quit smoking put on more weight. Overall, $27.4 \%$ of the patients received behavioural education $(\mathrm{BE}), 56 \%$ of them received behavioural education and nicotine replacement therapy (BE+NRT), $9.5 \%$ of them received $\mathrm{BE}+\mathrm{Bupropion}, 2.5 \%$ of them received $\mathrm{BE}+$ Varenicline, and $4.6 \%$ of them received BE+Bupropion+NRT treatments. The rates of quitting smoking were $15.2 \%, 43.7 \%, 52.2 \%, 66.7 \%$ and $45.5 \%$, respectively. With the administration of pharmacological treatment for a sufficient time, the rates of quitting smoking rose meaningfully $(\mathrm{p}<0.001)$.

Conclusion: Quitting smoking is a difficult process that has to be evaluated individually for every case. In this process, the administration of sufficient behavioural education and pharmacological treatment with sufficient time for appropriate individuals will increase the success rate.
\end{abstract}

Keywords: Methods of smoking cessation, smoking cessation, smoking cessation outpatient clinic

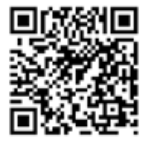

Received Date: 09.12.2013

Accepted Date: 08.03.2014

Address for correspondence

Zehra Yaşar, Department of Pulmonary Disease, Abant İzet Baysal University Faculty of Medicine, Bolu, Turkey

E-mail: zehraasuk@hotmail.com

(C) Copyright 2014 Turkish Respiratory Society (TRS) Eurasian J Pulmonol 2014

DOI: 10.5152/ejp.2014.48295

- Available online at www.eurasianjpulmonol.com

\section{INTRODUCTION}

Tobacco use is the primary cause of preventable diseases and deaths in the world. According to data of the World Health Organisation (WHO), there are 1.3 billion smokers in the world and approximately 5 million people lose their lives because of smoking-related illnesses. In Turkey, 100,000 people per year die early because of smoking. These numbers are estimated to rise to 8.4 million people in the world and 240,000 people in our country in 2030. It is reported that while the rate of tobacco use in developed countries falls, it is rising in developing countries. It is envisaged that $80 \%$ of tobacco-related deaths in the world will be in developing countries in $2030(1,2)$.

Turkey is among the countries where the rate of smoking is high; according to the WHO, the smoking rate of men is among the highest in the European region (3). One of the reasons for the high prevalence in our country is the low rate of smoking cessation. Although smokers frequently think that it is a habit without being aware that it is dependence, smoking causes dependence because of the nicotine it comprises. At all ages, tobacco has a higher dependence prevalence than all the other substances.

It is reported that $70 \%$ of smokers consider quitting and $80 \%$ of them have tried to quit smoking in one period of their lives $(4,5)$. Most smokers try to quit without any help and many of them start to smoke again in a short time (6). In order for smokers attempting to quit to be successful, along with 
factors causing the continuation of smoking, it should be dealt with on an individual and family basis, as well as pharmacologically. Socioeconomic and cultural factors play a critical role in determining who will start, who will quit and who will continue smoking.

Raising awareness in society in our country has increased the number of applications to smoking cessation clinics. The process of quitting smoking is supported by medical treatment and behavioural education in these clinics. In this study, the aim is to investigate the factors affecting the quitting smoking success of the patients followed in the smoking cessation outpatient clinic and the rate of quitting smoking in this clinic.

\section{METHODS}

In this study, 320 cases applying to Dogubeyazit Public Hospital Smoking Cessation Outpatient Clinic between June 2011 and June 2012 were included. Routine biochemical and hematological tests, respiratory function test, electrocardiography, and posteroanterior chest radiography were requested from the cases. Moreover the cases were requested to complete the FNDT, anxiety and depression assessment scale and the outpatient clinic's form including demographic data. The accompanying diseases of the cases and the medications they continuously use were recorded. The cases in whom the anxiety and depression assessment scales were high referred to the psychiatry outpatient clinic and their opinion was taken.

Approximately 20-30 minutes was allocated for the interview, which was conducted in a smoking cessation outpatient clinic. In this interview, after the general evaluations of the patients were made, behavioural education for smoking cessation and pharmacological treatment appropriate for the patient were started; outpatient follow-up with 15 day to 1 month intervals was recommended to the patients. The patients were called at certain time intervals by the assistant health staff to evaluate adaptation to the treatment and to remind them of the appointments. Whether the patients quit smoking or not was evaluated at the end of the $3^{\text {rd }}, 6^{\text {th }}$ and $12^{\text {th }}$ months of the patients follow-ups by outpatient clinic follow-ups and calling the patients. The treatments administered for the cases and the duration of treatments were recorded. Those who received the determined treatments for four months were considered to have received adequate treatment. The smoking cessation success at the end of a year for the 241 cases in whom the follow-ups were completed and the factors affecting success were evaluated.

The cases were divided into two groups as those who were successful and those who failed to quit smoking at the end of the 12 month follow-up. First, a comparison between the two groups with regard to demographic characteristics was made. Then, the cases were divided according to the treatments as those receiving behavioural education (BE), those receiving behavioural education and nicotine replacement therapy $(B E+N R T)$, those receiving $B E+B$ upropion, those receiving $B E+$ Varenicline and those receiving $B E+B$ upropion+NRT. In the behavioural education, it was tried to change the habitual thought patterns towards the individual himself and smoking. Suggestions were made to minimise and control the desire to smoke (7). Comparisons were made with regard to the demographic characteristics among the groups. Then, by forming groups according to the duration of treatments, the effects of them on the success of smoking cessation were compared.

\section{Statistical Analysis}

The statistical analyses were performed using IBM SPSS Statistics for Windows, Version 20.0 (Armonk, NY: IBM Corp.). The numerical variables showing normal distribution were depicted as mean \pm standard deviation, and those not showing normal distribution were depicted as median (minimum and maximum interval); the rates were depicted as (\%)n. The rates were compared by chi-square test or Fisher's exact test, the comparison of two not normally distributed independent groups were made by Mann-Whitney $U$ test and Kruskal-Wallis test was used when there were more than two groups. The independent predictors envisaging not being able to quit smoking was examined by logistic regression analysis. For the model adaptation, the Hosmer-Lemeshow test was used. Statistical significance level was taken as $p<0.05$. Ethics Committee Approval was taken (2013) from Abant İzzet Baysal University.

\section{RESULTS}

Overall, 320 people who applied to the smoking cessation outpatient clinic were evaluated and follow-ups could be completed in 241 of them [n: 145 (60.2\%) male, n: 96 (39.8\%) female]. Their mean age was $42.6 \pm 13.5$ (17-77 years); most of them were primary school graduates (34.0\%)(secondary school $26.6 \%$, high school $20.7 \%$, university $5.8 \%$ ). The median age at starting smoking again was 18 (10-40) and the period of smoking was 23 (2-156) packs.year.

Here, 167 of the cases (69.3\%) had considered quitting smoking, and 114 of them $(68.3 \%)$ had attempted to quit smoking. The reasons for starting smoking were mainly curiosity (45.6\%), trying to imitate somebody (45.2\%) and stress (45.2\%), while the most common difficulties faced when attempting to quit smoking were nervousness (73.7\%), craving smoking (51.8\%) and lack of concentration (39.5\%). The most frequent reasons increasing the desire for smoking were stress (68.0\%), drinking tea (53.5\%), eating (45.6\%) and drinking coffee $(17.4 \%)$. The desire to smoke was reported to increase in 114 cases $(47.3 \%)$ through years. The most common reason for application to the outpatient clinic to quit smoking and the emergence of smoking cessation thought was medical advice.

The cases were compared by dividing into two groups according to quitting smoking or not (Table 1). The rate of smoking cessation at the end of the first year was $37.3 \%$. In both groups, the age, gender, education level, marital status, ages at which smoking was started and the reasons for starting smoking were similar. There was no difference when cigarette consumption was calculated as packs.year. When the difficulties encountered in quitting smoking for both groups were compared, concentration difficulty $(p<0.001)$ and nervousness $(p=0.001)$ in particular were frequently detected in the group that was not able to quit smoking. The people in the group not being able to quit smoking were smoking more in their workplaces and the FNDT score was significantly higher $(p<0.001)$. In the group that quit smoking, putting on weight was significant $(p<0.001)$. There was no meaningful difference between the groups with respect to smoking cessation attempts beforehand and number of attempts. After the logistic regression analysis of the independent predictors envisaging not being able to quit smoking age [RR; 0.95 (95\% GA 0.9-0.99)], lack of concentration [RR; 13.6 (95\% GA 3.2-56.7)] and Fagerstrom scores (FSG) [RR; 3.2 (95\% GA 1.9-5.5)], were found to be significant (Table 2). Since all of the people quitting smoking received treatment for more than 30 days, the duration of treatment could not be put into regression analysis. 
Table 1. The characteristics of cases according to whether they quit smoking or not

\begin{tabular}{|c|c|c|c|c|c|c|c|}
\hline & $\begin{array}{l}\text { Not being able } \\
\text { to quit }\end{array}$ & $\begin{array}{l}\text { Quitting } \\
\text { smoking }\end{array}$ & p & & $\begin{array}{c}\text { Not being able } \\
\text { to quit }\end{array}$ & $\begin{array}{l}\text { Quitting } \\
\text { smoking }\end{array}$ & $\mathbf{p}$ \\
\hline $\mathrm{N}$ & 151 & 90 & & Economy & $1(0.7 \%)$ & 0 & 0.44 \\
\hline Gender(M/F) & $90 / 61$ & $55 / 35$ & 0.82 & Attempting to quit smoking & $70(46.4 \%)$ & $44(48.9 \%)$ & 0.7 \\
\hline Education & & & & Difficulty & & & \\
\hline Literate & $5(3.3 \%)$ & $5(5.6 \%)$ & & Lack of concentration & $37(52.9 \%)$ & $8(18.2 \%)$ & $<0.001$ \\
\hline Primary School & $47(31.1 \%)$ & $35(38.9 \%)$ & & Craving for cigarette & $38(54.3 \%)$ & $21(47.7 \%)$ & 0.49 \\
\hline Secondary School & $42(27.8 \%)$ & $22(24.4 \%)$ & & Mouth sore & $11(15.7 \%)$ & $12(27.3 \%)$ & 0.13 \\
\hline High School & $29(19.2 \%)$ & $21(23.3 \%)$ & & Headache & $15(21.4 \%)$ & $8(18.2 \%)$ & 0.67 \\
\hline Medical advice & $125(82.8 \%)$ & 75 (83.3\%) & 0.35 & None & $1(1.4 \%)$ & $1(2.3 \%)$ & 1.0 \\
\hline His/her own will & 15 (9.9\%) & $12(13.3 \%)$ & & Professional support & $7(4.6 \%)$ & $4(4.4 \%)$ & 0.94 \\
\hline Both & $11(7.3 \%)$ & $3(3.3 \%)$ & & Other smokers at home & $119(78.8 \%)$ & $70(77.8 \%)$ & 0.85 \\
\hline Reason of starting smoking & & & & Other smokers at the workplace & $65(43.0 \%)$ & $45(50.0 \%)$ & 0.29 \\
\hline Surroundings & $56(37.1 \%)$ & $24(26.7 \%)$ & 0.097 & Goldbricking & $13(1-30)$ & $10(1-25)$ & 0.001 \\
\hline Proving oneself & $39(25.8 \%)$ & 31 (34.4\%) & 0.15 & Use of cigarette making dependent & $24(15.9 \%)$ & $7(7.8 \%)$ & 0.069 \\
\hline Curiosity & $71(47.0 \%)$ & 39 (43.3\%) & 0.58 & Putting on weight & $13(8.6 \%)$ & $61(67.8 \%)$ & $<0.001$ \\
\hline Desire of imitating somebody & $66(43.7 \%)$ & $43(47.8 \%)$ & 0.54 & Quitting smoking & & & \\
\hline Medical advice & $106(70.2 \%)$ & $63(70 \%)$ & 0.97 & Eating & $62(41.1 \%)$ & $48(53.3 \%)$ & 0.06 \\
\hline Fear of Disease & $57(37.7 \%)$ & $29(32.2 \%)$ & 0.39 & Stress & $100(66.2 \%)$ & $64(71.1 \%)$ & 0.43 \\
\hline Disease & 51 (33.8\%) & 37 (41.1\%) & 0.25 & Anxiety & $6(2-12)$ & $7(4-10)$ & 0.97 \\
\hline Social pressure & $4(2.6 \%)$ & $3(3.3 \%)$ & 0.76 & Depression & $7(4-12)$ & $7(4-11)$ & 0.43 \\
\hline Pregnancy & $3(2.0 \%)$ & $1(1.1 \%)$ & 0.61 & FNDT score & $8(4-9)$ & $6(3-9)$ & $<0.001$ \\
\hline Good example & $8(5.3 \%)$ & 0 & 0.026 & & & & \\
\hline
\end{tabular}

FNDT score: Fagerstrom nicotine dependence test score

Of the cases, $66(27.4 \%)$ of them received $\mathrm{BE}, 135(56 \%)$ received $\mathrm{BE}+\mathrm{NRT}, 23(9.5 \%)$ received $\mathrm{BE}+$ Bupropion, $6(2.5 \%)$ received $\mathrm{BE}+-$ Varenicline, and $11(4.6 \%)$ received $B E+B$ upropion+NRT treatments. Overall, $15.2 \%$ of the cases only receiving behavioural education, $43.7 \%$ of those receiving NRT, $52.2 \%$ of those receiving bupropion, $66.7 \%$ of those receiving varenicline and $45.5 \%$ of those receiving bupropion and NRT were able to quit smoking $(p<0.001)$. When the duration of the treatments received were evaluated, it was noted that if the duration of pharmacological treatment was sufficient, smoking cessation rates significantly increased (Table 3 ).

\section{DISCUSSION}

When the dependence mechanisms of the cigarette and the neurological and psychological-behavioural reasons leading to smoking addiction are taken into consideration, smoking addiction can be seen to be a chronic and repetitive state which many smokers have to struggle with for a long time. Every year, almost three-quarter of smokers attempt to quit smoking, which becomes unsuccessful within a few days. Smoking cessation outpatient clinics have an important role in tobacco control. The number of smoking cessation outpatient clinics in our country is increasing day by day. 
In our study, smoking cessation success in the 12th month was calculated as $37.4 \%$. In other studies conducted in our country, smoking cessation success at the end of the first year changes between $21 \%$ and $48 \%$ (8-13). Studies investigating the effects of sociodemographic factors, additional diseases and the characteristics of smoking on smoking cessation success were carried out and it was reported that smoking cessation success is related with age, gender, socioeconomic status and nicotine dependence (14-17). Monso et al. (14) suggested that age and gender are effective factors in smoking cessation. Fernandez et al. (18), on the other hand, reported that smoking cessation increases with age independent of gender. Besides the studies reporting that men can more easily quit smoking, there are studies emphasising that age and gender have no effect on smoking cessation $(9,10,12,19)$. Similarly, in our study, it was found that age and gender have no effect on smoking cessation.

While in some studies examining the effect of education level on the success of smoking cessation it was reported that in the groups having a high level of education, the rate of smoking cessation is high $(20,21)$, there was no difference found between quitting smoking and different education levels $(9,14)$. In our study, there was no difference between the groups quitting smoking and those not being able to quit smoking with regard to the education level. This may be due to the fact that most of the cases in our study are graduates of primary school. When compared with the findings of a study conducted in our country including mostly cases with education levels

Table 2. The examination of the independent predictors in envisaging not being able to quit smoking by logistic regression analysis

\begin{tabular}{|l|c|c|}
\hline Risk Factor & RR (95\% GA) & p \\
\hline Age & $0.95(0.9-0.99)$ & 0.046 \\
Gender (woman) & $1.29(0.36-4.69)$ & 0.70 \\
$\begin{array}{l}\text { Education level (being graduate } \\
\text { of high school or above) }\end{array}$ & $0.33(0.08-1.29)$ & 0.11 \\
Having a profession & $2.1(0.6-7.6)$ & 0.25 \\
Nervousness & $0.6(0.18-2.28)$ & 0.50 \\
Lack of concentration & $13.6(3.2-56.7)$ & $<0.001$ \\
FSG score & $3.2(1.9-5.5)$ & $<0.001$ \\
The number of people smoking & $1.07(0.98-1.17)$ & 0.12 \\
at the workplace & & \\
\hline \multicolumn{2}{l|}{ RR: Relative risk; Cl: Confidence Interval; FSG: Fagerstrom } \\
\hline
\end{tabular}

of high school or above, it was found that their smoking cessation rates at the end of the first year were no different than the smoking cessation rates of the group in our study (20).

It was suggested in previous studies that the number of cigarettes smoked per day, FNDT and packs.year values are effective factors in smoking cessation. Also, there are studies suggesting that these factors are correlated with the success of smoking cessation, but there are also studies reporting that high nicotine dependence and smoking too much are correlated with low smoking cessation rates (17, 21). In our study, while the number of cigarettes smoked per day was higher in the group that quit smoking, the starting age of smoking and the value of packs.year were similar in both groups. Gorecka et al. (16) suggested that the low FNDT score was related to smoking cessation success. Similarly, there was a meaningful difference between the two groups in our study as well. The FNDT scores were meaningfully lower in the group that quit smoking.

Most of the cases in our study attempted to quit smoking, but their attempts failed. The rate of those receiving professional support was quite low. While some studies in the literature suggest that unfavourable experience has negative effects on smoking cessation success, others report that it does not have any effect $(6,8,22,23)$. There was no difference detected between the two groups. The application reason for most of the cases to our outpatient clinic was medical advice. It was also indicated in previous studies that the medical advice suggested by the doctor to all patients defined as smokers has an important place in tobacco control studies $(24,25)$. There was no effect found on whether there were others smoking at the patients' home or not on smoking cessation treatment. This is similar to other studies conducted in our country $(8,13)$. In spite of this, it was seen that there was more smoking at the work places of the group that was not able to quit smoking. Spending longer time at the work places, the fact that there are more stress factors in the work environment and taking regular breaks may be effective factors for not being able to quit smoking.

When the adverse effects observed during smoking cessation are evaluated it can be suggested that the most common complaints are nervousness, difficulty concentrating and craving smoking. It is considered that these findings are related to the lack of nicotine. Our findings are also similar to those of the study undertaken by Demir et al. When the factors increasing smoking desire are examined in our study, stress was found to be the most important one. Hospital anxiety and depression scores were not significantly different be-

Table 3. The effect of duration of therapy on quitting smoking

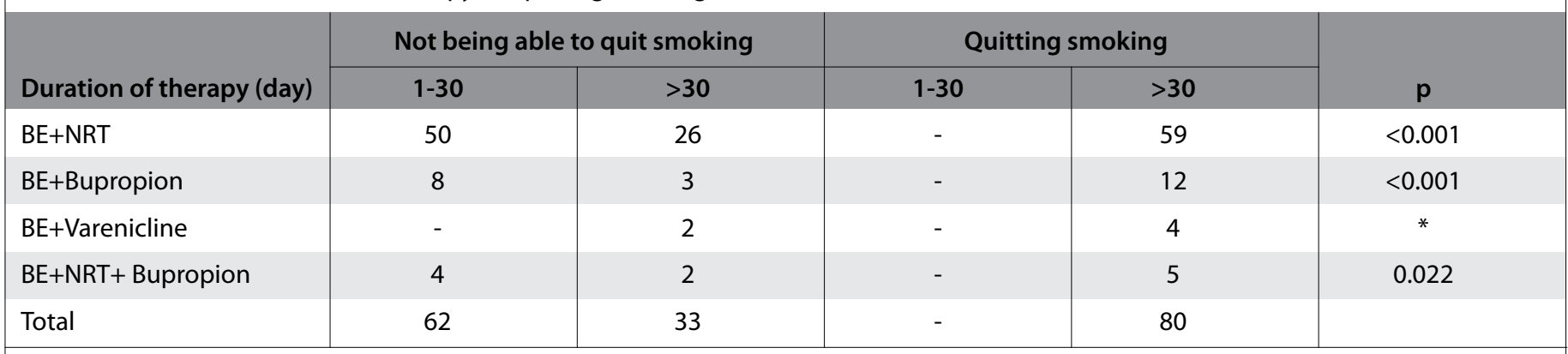

BE: Behavioural education; NRT: Nicotine replacement therapy

* Since all the patients in the BE+Varenicline group received sufficient time of treatment, statistics could not be produced. 
tween the groups. It was thought that this was due to reference of the applying patients having high anxiety and depression scores in the centres where joint studies with the department of psychiatry can be performed.

When the patients were compared according to the treatment they received, it was found that the smoking cessation rate significantly increased in patients to whom pharmacological treatment was added to BE. As pharmacological treatment was mostly NRT, bupropion, varenicline and combined treatment was planned. Since our study was not carried out in the period when bupropion and varenicline were supplied free of charge by the Health Ministry, because of the financial situations of the cases, the number of the bupropion and varenicline medicated patients was lower since they were more expensive than NRT. Besides, there were also patients for whom pharmacological treatment was started but who quit treatment since they could not afford the treatment costs. Şahbaz et al. (20) emphasised that smoking cessation results obtained by different pharmacological treatments were similar. Önen et al., on the other hand (22), indicated that pharmacological treatment alone is superior over $\mathrm{BE}$ and bupropion is more effective than NRT. In our study as well, the effect of the added pharmacological treatment on the success of smoking cessation was significantly high. Administering pharmacological treatment for an adequate time period also significantly increased smoking cessation rates. Due to the fact that the number of patients taking Varenicline was low and those who took it did not receive the treatment for a sufficient time, a comparison could not be made between the treatment period and smoking cessation success. The increase in the rate of smoking cessation by the pharmacological treatment led us to consider that the medication is noteworthy with regard to being evaluated under repayment.

In smoking cessation treatment, the importance of BE is focused on, as behavioural education underlies supporting the patient's own effort and short advices (26). It was indicated that if the duration of therapy increased, the effect of the therapy also increased (27). In a study comparing BE and NRT, there was no difference foundbetween them. In our study, BE was given individually for those cases who did not want to receive pharmacological treatment or for those to whom pharmacological treatment could not be administered. When compared with the other treatment groups, the smoking cessation success of BE was significantly lower. In a study carried out in our country, it was indicated that the addition of psychodrama practice on the attempt of smoking cessation increased smoking cessation rates. (28).

In our study, NRT forms were used together with nicotine patches and nicotine chewing gum. There are studies reporting that the use of nicotine patch and the other forms together increase the rate of smoking cessation success (29). Overall, $43 \%$ of the cases who received nicotine replacement therapy were able to quit smoking. Argüder et al. reported the smoking cessation success rate by NRT to be $36.2 \%$. Smoking cessation success significantly increased in the cases receiving NRT for longer than one month.

West et al. (30) compared bupropion treatment with NRT and found that the smoking cessation rate for longer than one year was higher in the group taking bupropion. Similarly, in our study, it was also found that smoking cessation rates of the group receiving bupropion and BE was higher in comparison to the group receiving NRT. Howev- er when compared with varenicline, the rates were found to be lower. On the other hand, when the duration of therapy was adequate, smoking cessation success rates increased significantly. This was similar to the previously conducted studies $(9,20)$. In the literature, the success rate 6 months later with varenicline was reported to be $49.5 \%$. In our study it was seen that smoking cessation success of varenicline treatment was lower when compared with other treatment alternatives. The reason of its being higher than the previously reported values may be due to the fact that very few patients received the treatment and that all of the patients received the treatment for an adequate time period. Since there was no case group receiving the treatment for an inadequate time period, a comparison could not be made between the duration of therapies. Therefore, studies that will compare the case group taking more varenicline and the duration of therapies may give reliable results.

\section{CONCLUSION}

In our study, it was found that factors such as gender, age, education and demographic data are not effective and that the dependence score was important. It was detected that smoking cessation rates increase by the use of the suitable pharmacological treatment for sufficient time in smoking cessation outpatient clinics under close follow-up.

Administering adequate $\mathrm{BE}$ and cooperating with the department of psychiatry to struggle more easily with the factors such as stress, concentration difficulty and nervousness may increase smoking cessation rates. For this, there is a need for comprehensive studies that will be carried out with the department of psychiatry in the future.

Ethics Committee Approval: Ethics committee approval was received for this study from the ethics committee of Abant Izzet Baysal University.

Informed Consent: Written informed consent was obtained from patients who participated in this study.

Peer-review: Externally peer-reviewed.

Author Contributions: Concept - Z.Y., Ö.K.K.; Design - Z.Y., F.T.; Supervision F.T., A.K.; Resource - Z.Y., A.K.; Materials - Z.Y.; Data Collection\&/or Processing - Z.Y., Ö.K.K.; Analysis\&/or Interpretation - Z.Y., F.T.; Literature Search - Ö.K.K., A.K.; Writing - Z.Y.Ö., K.K.; Critical Reviews - F.T., A.K.

Conflict of Interest: No conflict of interest was declared by the authors.

Financial Disclosure: The authors declared that this study has received no financial support.

\section{REFERENCES}

1. Mathers CD, Loncar D. Projections of global mortality and burden of disease from 2002 to 2030. Plos Med 2006; 3: e442.

2. World Health Organization. Health Report 2002. Geneva 2002. http:// www.who.int/whr/2002/en/whr02-en.pdf, Access date: 09.05.2013.

3. Bilir N, Özcebe $H$, Aslan D, Ergüder T. Küresel Tütün Salgını Raporu. MPOWER paketi. Ankara; $2008 \mathrm{http} / /$ whqlibdoc.who.int/publications/2008/9789241596282-tur.pdf. Access date: 12.5.2013.

4. Centers for Disease Control and Prevention (CDC). Cigarette smoking among adults-United states,1995.MMWR Morb Mortal Wkly Rep 1997; 46: 1217-20.

5. US Department of Health and Human Services. Reducing the health consequences of smoking: 25 years of progress; a report of the Surgeon General. Rockville MD: US Department of Health and Human Services, Public Health Service, Centers for Disease Control, Centers for Chronic Disease Prevention and Health Promotion, Office on Smoking and Health, 1989; DHHS Publication No.(CDC)89-8411.

6. Hughers JR, Gulliver SB, Fenwick JW, Valliere WA, Cruser K, Pepper S, et al. Smoking cessation among self-quitters. Health Psychol 1992; 11: 331-4. 
7. European Smoking Cessation Guidelines: The authoritative guide to a comprehensive understanding of the implications and implementation of treatments and strategies to treat tobacco dependence. English Version 03.10.2012. http://www.ensp.org/escg.

8. Solak ZA, Telli CG, Erdinç E. Results of Smoking Cessation Program. Turk Thorac J 2003; 4: 73-7.

9. Argüder E, Karezli A, Hezer H, Kılıç H, Er M, Hasanoğlu HC, et al. Factors Affecting the Success of Smoking Cessation. Turk Thorac J 2013; 14: 81-7.

10. Sağlam L. Investigation of the results of a smoking cessation clinic and the factors associated with success. Turk J Med Sci 2012; 42: 515-22.

11. Çan G, Öztuna F, Özlü T. The Evaluation of Outpatient Smoking Cessation Clinic Results. Tuberk Toraks 2004; 52: 63-74.

12. Demir T, Tutluoğlu B, Koç N, Bilgin L. One-Year Follow up Results of Smoking Cessation Outpatient Clinic. Tuberk Toraks 2004; 52: 63-8.

13. Salepçi B, Fidan A, Oruç Ö, Torun E, Çağlayan B, Kader ŞN. Success Rates in Our Smoking Cessation Clinic and Factors Affecting It. Turk Thorac J 2005; 6: 151-8.

14. Monso E, Campbell J, Tonnosen P, Gustavsson G, Morera J. Sociodemographic predictors of success in smoking intervention. Tob Control 2001; 10: 165-9.

15. Osler M, Prescott E. Psychosocial, behavioral and health determinants of successful smoking cessation: a longitudinal study of Danish adults. Tob Control 1998; 7: 262-7.

16. Górecka D, Bednarek M, Nowiński A, Puścińska E, Goljan-Geremek A, Zieliński J. Diagnosis of airflow limitation combined with smoking cessation advice increases stop smoking rate. Chest 2003; 123: 1916-23.

17. Kenford SL, Fiore MC, Jorenby DE, Smith SS, Wetter D, Baker TB. Predicting smoking cessation. Who will quit with and without the nicotine patch. JAMA 1994: 271; 589-94.

18. Fernandez E, Garcia M, Schiaffino A, Borras JM, Nebot M, Segura A. Smoking initiation and cessation by genger and educational level in Catalonia, Spain. Prev Med 2001; 32: 218-23.
19. Renaud JM, Halpern MT. Clinical management of smoking cessation: patient factors affecting a reward -based approach. Patient Prefer Adherence 2010;4: 441-50.

20. Şahbaz S, Kılınç O, Günay T, Ceylan E. The Effects of Smoking Properties and Demographic Properties on the Results of Smoking Cessation Therapy. Turk Thorac J 2007; 8: 110-14.

21. Janson C, Kunzli N, deMarco R, Chinn S, Jarvis D, Svanes C, et al. Changes in active and passive smoking in European Community Respiratory Health Survey. Eur Respir J 2006; 27: 517-24.

22. Onen ZP, Sen E, Eriş Gülbay B, Oztürk A, Akkoca Yıldız O, Acıcan T, et al. Comparing the effectiveness of different treatment modalities on the smoking cessation rates. Tuberk Toraks 2010; 58: 385-92

23. McEwen A, West R. Do implementation issues influence the effectiveness of medications? The case of nicotine replacement theraphy and bupropion in UK Stop Smoking Services. BMC Public Health 2009;9: 28.

24. Eckert $\mathrm{T}$, Junker $\mathrm{C}$. Motivation for smoking cessation: what role do doctors play? Swiss Med Wkly 2001;131: 521-6.

25. McCullough A, Fisher M, Goldstein AO, Kramer KD, Ripley-Moffitt C. Smoking as a vital sign: prompts to ask and assess increase cessation counseling. J Am Board Fam Med 2009; 22: 625-32.

26. Williams $J M$, Ziedonis $D$. Adressing tabacco among individuals with a mental illness or an addiction. Addict Behav 2004; 29: 1067-83.

27. Örsel O, Örsel S, Alpar S, Ucar N, Sipit T, Kurt B. The comparison of nicotine replacement therapy and behavioral education in smoking cessation: A study of naturalistic follow-up. Tuberk Toraks 2005; 53: 354-61.

28. Aytemur ZA, Pişmişoğlu B, Kılınç O, Pişmişoğlu E, Hacıevliyagil SS, Karaman C. Intensive clinic intervention plus psychodrama in smoking cessation and effects on cessation outcome. Turkiye Klinikleri J Med Sci 2012; 32: 630-7.

29. Stead LF, Perera R, Bullen C, Mant D, Lancaster T. Nicotine replacement theraphy for smoking cessation. Cochrane Database Syst Rev 2008: 1:CD000146.

30. West R, Mcneill A, Raw M. Smoking cessation guideline for health professionals: An update. Thorax 2000;55: 987-99. 